\title{
Developing a Greenometer for green manufacturing assessment
}

\author{
Ahmed H. Salem a , Ahmed M. Deif ${ }^{\text {b, * }}$ \\ a School of Management of Technology, Nile University, Cairo, Egypt \\ ${ }^{\mathrm{b}}$ Industrial Technology and Packaging Dept., California Polytechnic State University, CA, USA
}

Keywords:

Greenness assessment

Data envelopment analysis (DEA)

Geometric mean method

Manufacturing (GMM)

\begin{abstract}
A B S T R A C T
In this paper a toolbox (Greenometer) to assess the greenness level of manufacturing companies is proposed. The assessment approach is based on capturing the relative greenness position of any company among other industries from different sectors as well as within the same sector. The assessment was based on selected greenness attributes and their composing indicators at each of the two levels of the developed Greenometer. Geometric Mean Method (GMM) was adopted to be the generic assessment technique for cross industries greenness evaluation, while Data Envelopment Analysis (DEA) was employed to assess the greenness level of intra-industries layer. Three different industrial applications were used to demonstrate the applicability of the developed Greenometer. Results highlighted how the proposed tool can be a useful for manufacturing managers not only in understanding their green performance position at various levels, but also aiding them in their green transformation/improvement efforts. Specifically, the Greenometer assessment scores will help in setting plans through highlighting prioritized areas of required improvement as well as offering quantitative targets and tracking metrics along the transformation journey.
\end{abstract}

\section{Introduction}

A sustainability revolution is now taking place to address the challenges of production and consumption in this century. Continuously published statistics and research capturing the rate of resource consumption and industrial growth has increased public awareness and concern over the environmental and social impact of the failures of industrialization: the environmental disaster is being seen for what it really is (Barber, 2007). Sustainability is about building a society in which a proper balance is created between economic, social and ecological aims.

Green manufacturing is at the center of this sustainability revolution. The term green manufacturing was coined to reflect the new manufacturing paradigm that implements various green strategies (objectives and principles) and techniques (technology and innovations) to become more eco-efficient (Deif, 2011). There are strong customer, government and business pressures to embrace green manufacturing. This led to the development of multiple research and practical attempts to explain and guide green

\footnotetext{
* Corresponding author.

E-mail address: adeif@calpoly.edu (A.M. Deif).
}

manufacturing transformation requirements and approaches. However, and as in most previous manufacturing transformation paradigms (like lean and agile manufacturing), the techniques and the "how" were always the focus of these attempts with far less attention given to the assessment approaches. Green manufacturing is no exception.

The conventional manufacturing wisdom states that one cannot improve what cannot be measured. This applies also to the effort of improving (transforming) manufacturing greenness level. Among the challenges of measuring the greenness level of manufacturing systems are: What parameters define manufacturing greenness? How can these parameters be captured or measured? And what approach can be used to quantify the assessment process in order to act as both a measuring tool as well as a tracking (benchmarking) tool? This research is an attempt to answer some of the previous questions through developing a Greenometer that offers relative greenness assessment among different industries. The proposed Greenometer is based on an integrated approach that employs geometric mean method (GMM) at a strategic layer to conduct an inter-sector relative assessment as well as a data envelopment analysis (DEA) at the tactical layer to conduct an intra-sector relative assessment. 


\section{Literature review}

In this section different aspects of greenness assessment processes will be reviewed. The first aspect is concerned with identifying the greenness assessment level. Examples of this aspect include the work of (Sarkar et al., 2011) who mentioned that National Institute of Science and Technology (NIST) categorized the manufacturing levels into different measurement units namely: product, process, facility, corporation, sector, country and world. Haapala et al. (2013) classified the green measurement units into machine, operation, process and system levels. Assessing the greenness level at any measurement units has to stick to some clear assessment indices. Linke et al. (2013) classified the manufacturing greenness measurements to be at the levels of companies, facilities, processes and products. Zhang et al. (2013) sorted the sustainable manufacturing measurement scales into two levels, operational (micro) scale and enterprise (macro) scale. Al-Fandi (2011) proposed that the green manufacturing assessment has the following scopes: manufacturing processes, enterprise activities and manufacturing process improvement framework. Venegas et al. (2016) conducted their research in new manufacturing level as they were concerned with assessing the greenness level of industrial parks as a manufacturing level.

The second aspect of greenness assessment focused on determining the assessment parameters and attributes. Examples of this aspect include the work of (Yang et al., 2003) who indicated that greenness attributes should follow principles such as purposefulness, systematicness and completeness, scientificness, comparableness, manipulability and independence to build up green assessment system. They also categorized the environmental attributes based on environmental standards issued by ISO into four main attributes; environment, resources, energy and economy. Qingsong et al. (2010) selected the same attributes to conduct his green assessment model. On the other hand (Joung et al., 2012), categorized the environmental attributes into five different categories namely; environmental stewardship, economic growth, social well-being, technological advancement and performance management. Ziout et al. (2013) sorted the different sustainable manufacturing attributes into three main sets; economical, environmental and social attributes. Romvall et al. (2011) developed a Green performance map (GPM) using ISO 14031 internal environmental performance indicators namely; management performance indicators (efforts) and operational performance indicators (physical performance). Other researchers used specific environmental attributes, such as energy performance attributes like in (Driscoll and Cusack, 2013) and (Azadeh et al., 2007).

The third aspect of the assessment process focused on the selection of greenness indicators. According to (Hue et al., 2015) the selection process of indicators should follows a systematic approach. They identified the elements of indicators as follows: quantification method, unit of measurement, improvement goal and the period of measurement. Qingsong et al. (2010) used the most common indicators for the selected attributes including 17 environmental indicators, 8 energy indicators, 7 resources indicators and 7 economic indicators. These indicators represent the core perspective of each attribute. For example, energy utilization and energy efficiency are considered as energy attribute's indicators. Natural resources consumption is considered as a resources attribute indicator. In this study the process of indicators selections followed the previous systematic approach and adopted the standards from the ISO 14000 families of environmental management system as well as the United States environmental protection agency (US. EPA).
The final considered aspect relates to the assessment techniques used to capture manufacturing greenness level. A popular approach used in many research is the analytical hierarchical process (AHP) due to its ability to combine multiple assessment attributes at different levels with different weights. Examples of this approach include the work of (Ziout et al., 2013) and (Ruby and Alvin, 2013). Fuzzy logic is widely applied also in greenness assessment due to its ability to capture qualitative and quantitative parameters. Vinodh (2011); Wang et al. (2005); Govindan et al. (2015) are examples of such fuzzy logic applications. Data Development Analysis is also a common tool for relative assessment of greenness performance. Examples of DEA use in this field include the work of (YOU, 2009); (Teresa et al., 2012); (Yang et al., 2003). Other approaches include the application of mapping techniques like in (Romvall et al., 2011); (TCS, 2009), simulation (Al-Fandi, 2011), life cycle assessment LCA in (Qingsong et al., 2010) and the work of (Nouira et al., 2014) who developed an optimization model in order to assess the greennessdependent demand of a process manufacturing level. A good review on various greenness assessment techniques at different manufacturing levels and scope can be found in (Al-Fandi, 2011), which support the selection of GMM and DEA as effective candidates for the assessment approaches in the Greenometer.

Unlike previous developed metrics, the proposed Greenometer is more comprehensive in its measuring scope. It integrates the previous reviewed aspects of the literature into a new assessment toolbox. The Greenometer toolbox aims at comparing greenness level between different industries (cross industry layer) and also compare greenness level for the specific selected industry within its own sector (intra-industries layer). This multilayer relative assessment approach is an addition to the existing literature of greenness level measurement and it will act as a generic toolbox for different industrial systems.

\section{Multilayer Greenometer development}

The Greenometer assessment is achieved through an integrated multistage procedure via its two layers. The first layer evaluates the relative greenness level of an industry with respect to an ideal system. This relative dimensionless assessment helps positioning the evaluated industry with respect to other industries through comparing their scores. Thus this layer is referred to as cross industry level (CIL). The second layer is dedicated to assess the greenness level

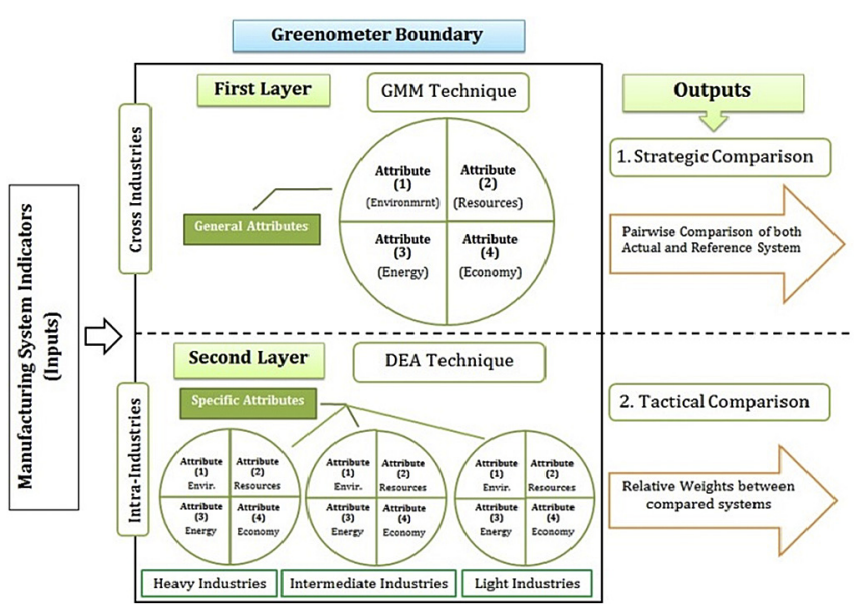

Fig. 1. Greenometer framework and components. 
Table 1

CIL assessment attributes and their respective indicators.

\begin{tabular}{ll}
\hline Attribute & Indicators \\
\hline Environment & $\begin{array}{l}\text { Solid waste, water waste disposal rate, greenhouse gas (GHG), } \\
\text { industrial emissions. }\end{array}$ \\
Resource & $\begin{array}{l}\text { Material scrap rate, utilization of raw material, natural resources } \\
\text { consumption, the RE's rates (Reuse, Reduce, Repair, Recycle, }\end{array}$ \\
Energy & $\begin{array}{l}\text { Recover, Remanufacture). } \\
\text { Fuel productivity, electricity efficiency, energy utilization rate, } \\
\text { solar energy usage. }\end{array}$ \\
& $\begin{array}{l}\text { Return on environmental investment, environmental penalties } \\
\text { cost, environmental expenses }\end{array}$ \\
\hline
\end{tabular}

of an industry with respect to similar ones in the same sector. Such assessment leads to a more specific positioning among competitors and referred to as intra-industry layer (IIL). Assessment criteria of both layers and their techniques are briefly explained next. The overall Greenometer framework is shown in Fig. 1. Appendix 1 shows different captions of the developed multilayer Greenometer toolbox including input page and the outputs of both layers.

\subsection{Cross industries layer (CIL)}

In this layer the greenness assessment is based on relative evaluation score of the considered industry against an ideal (datum) virtual system. The comparison is carried out using four generic attributes and each attribute includes generic environmental indicators. The attributes and their indicators are outlined in Table 1 . The indicators in the table are calculated as percentages of the overall production rate. This kind of normalization is an attempt to manage the magnitude differences among industries with respect to these indicators.

The general attributes and indicators in the datum system were carefully selected from different sources including ISO 14000 families of environmental management system (EMS) and United States environmental protection agency (U.S. EPA).

As mentioned earlier, geometric mean method (GMM) is an efficient tool to combine these selected different attributes with their variable data levels (Mittal et al., 2016); (Ziout et al., 2013). Using GMM ranking method, the main four attributes for both the considered system and the datum virtual system, are compared to get a final ranking weights for each system relative to the other one. GMM is a participatory multiple criteria decision making (MCDM) process. It is an extended and improved technique of analytical hierarchy process (AHP) where criteria weights of GMM are derived through the AHP eigenvalue technique which involves the decision makers in pairwise comparison of both alternatives and criterion. Based on (Nordström et al., 2012), the geometric mean of the judgments of all stakeholders for each element in the pairwise comparison matrices is calculated in equation (1) as follows:

$$
\left(\prod_{t=1}^{k} m_{i j}^{t}\right) \forall i, j,
$$

where $m_{i j}^{t}$ is the element in the pairwise comparison matrix for stakeholder $t$ when criterion $i(i=1,2, \ldots q)$ is compared with criterion $j$. Similarly, the geometric means of the judgment of all stakeholders are calculated from the matrices, where alternatives are compared for each criterion as shown in equation (2):

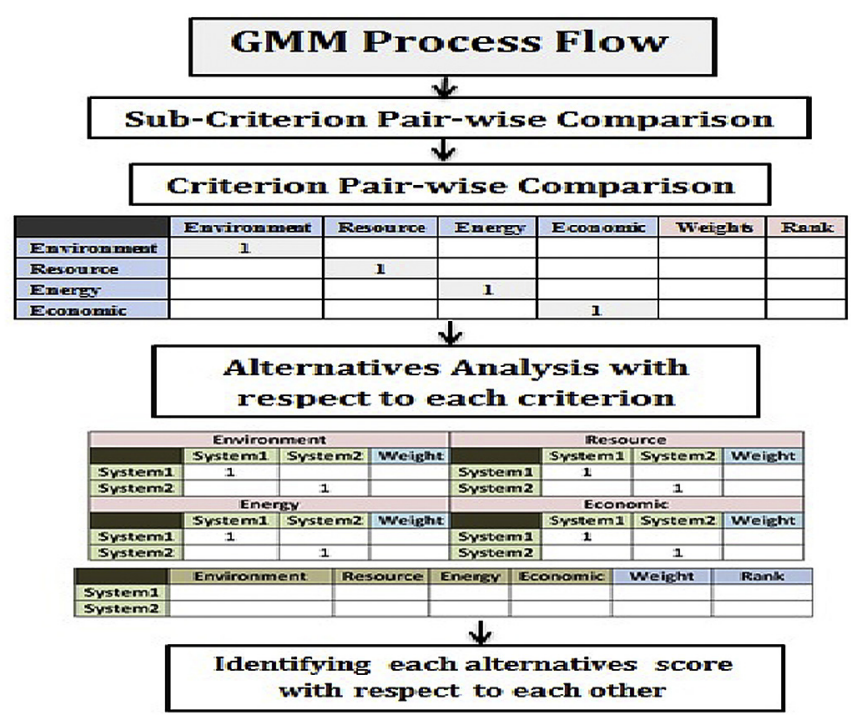

Fig. 2. GMM approach in the CIL of the Greenometer.

$\left(\prod_{t=1}^{k} m_{s v}^{t i}\right) \forall s, v$

where $m_{s v}^{t i}$ is the element in the pairwise comparison matrix for stakeholder $t$ when alternative $s$ is compared with alternative $v$ for criterion $i$.

This will result in one matrix aggregated preferences for the criteria and $q$ matrices with aggregated preferences for the alternatives in terms of each criterion. The overall implementation of GMM in the CIL of the proposed Greenometer is shown in Fig. 2. A survey was conducted to solicit the weights values (judgments) of the selected four attributes from ten industrial and manufacturing environmental experts (stakeholders). Although, subjectivity of experts' opinion is a valid concern, having multiple experts' opinion from different fields and using consistency analysis were used to mitigate and assess this induced subjectivity. Using equations (1) and (2), the weights for each of the four assessment attributes were calculated as shown in Table 2 (a). The consistency of the calculated weight were confirmed through a consistency analysis (shown in Appendix 2) which results are shown in Table 2(b) as outlined in Saaty (1977).

The CIL receives each indicators' values of the evaluated system where they are processed to get the final attributes' weights of the evaluated system then these weights are scaled relative to the ideal system which is represented by a fixed ruler scale (see Fig. 3). For example, if the attribute's average of Energy is $70 \%$ and since it contains positive indicators, the positive ruler will be used, with the relative weight will be 5 while if another attribute like Environment which contains negative indicators is considered, the negative ruler will be selected, thus the relative weight will be $1 / 5$. Next, the relative attributes' weights are processed with the pairwise matrix of the criteria weights against the datum system that scored for example $90 \%$ in each of the previous attributes. The final relative weight of the two compared systems are then generated in a dimensionless format so that if the evaluated system has an attribute value of $100 \%$ that means it reached the best performance (see Fig. 4 for a sample of CIL 
Table 2

(a) Criterion pairwise matrix and calculated weights, (b) Consistency analysis.

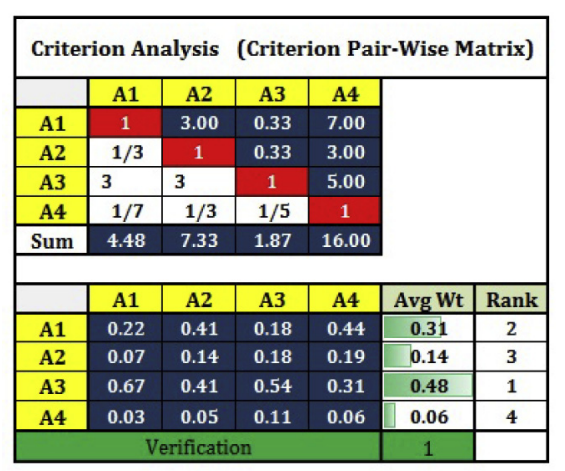

(a)

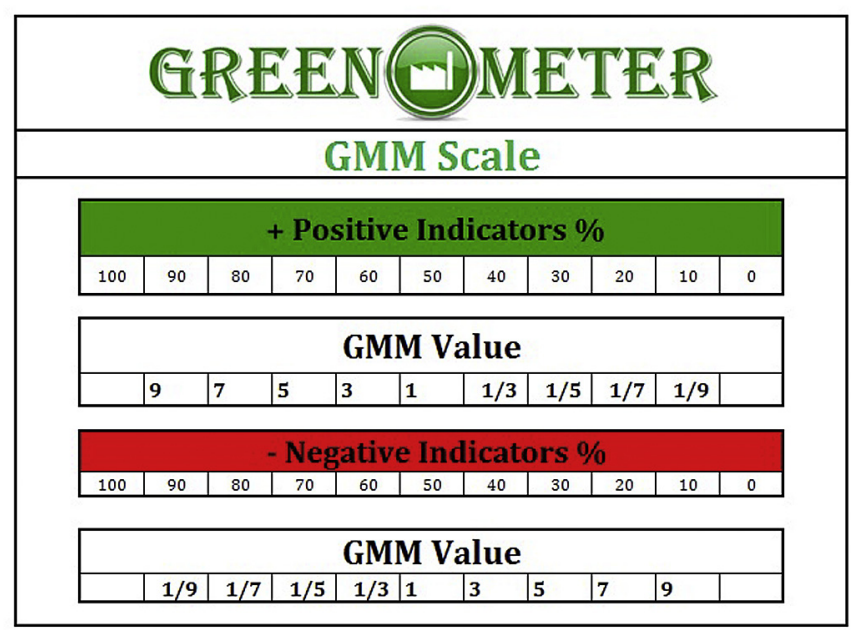

Fig. 3. Caption of GMM scaling mechanism.

output and Appendix 1 for captions of the GMM analysis in the developed toolbox).

\subsection{Intra-industry layer (IIL)}

In this layer, industries at the same sector are compared to one another from a greenness performance perspective. Industrial sectors are classified, based on the various environmental

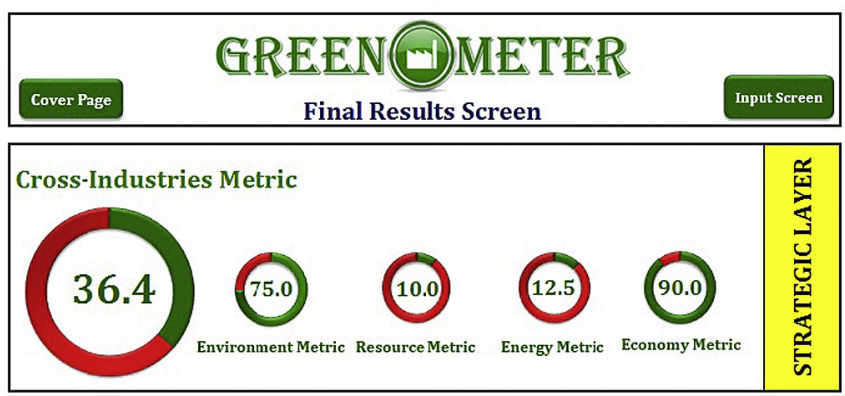

Fig. 4. Sample of CIL relative assessment output.

\begin{tabular}{|c|c|c|c|c|c|c|}
\hline \multicolumn{7}{|c|}{ Consistency Analysis } \\
\hline A1 & 0.31 & 0.43 & 0.16 & 0.43 & 1.34 & 4.29 \\
\hline $\mathrm{A} 2$ & 0.10 & 0.14 & 0.16 & 0.19 & 0.59 & 4.12 \\
\hline $\mathrm{A} 3$ & 0.94 & 0.43 & 0.48 & 0.31 & 2.16 & 4.48 \\
\hline $\mathrm{A4}$ & 0.04 & 0.05 & 0.10 & 0.06 & 0.25 & 4.06 \\
\hline \multicolumn{6}{|c|}{$\lambda(\max )$ (Eigen Value) } & 4.24 \\
\hline \multicolumn{6}{|c|}{ Consistency Index } & 0.07904 \\
\hline \multicolumn{6}{|c|}{ Consistency Ratio } & 0.0878 \\
\hline
\end{tabular}

(b)

standards such as ISO families and U.S. EPA, into either light industries, intermediate industries or heavy industries. This type of assessment complements the one conducted in the above layer through offering more tactical positioning of how the considered industry performs with respect to its competitors. This layer uses the data envelop analysis DEA approach for this comparative assessment. Fig. 5 shows how the DEA implemented at the IIL layer.

DEA was firstly introduced by (Charnes et al., 1979) as a nonparametric linear programming-based technique to measure the relative efficiencies of different decision making units (DMUs) which are the selected companies in each case. An optimal frontier DMU is created based on the different inputs and outputs of the different DMUs, then each DMU is being evaluated according to this optimal virtual frontier DMU. There are two different versions of DEA: the output-oriented DEA model where the linear programing model aims to maximize the DMU outputs with the same inputs, and the input-oriented DEA model which aims to minimize the inputs with keeping the outputs amount unchanged. In the Greenometer, since environmental assessment outputs are undesirable, the input oriented version is selected in the analysis of this layer.

DEA model should have at least one desirable output in order to obtain accurate efficiency results. However, as just mentioned, almost considered environmental outputs are undesirable. To fix this problem, a non-linear monotonic decreasing transformation

\section{Inputs}

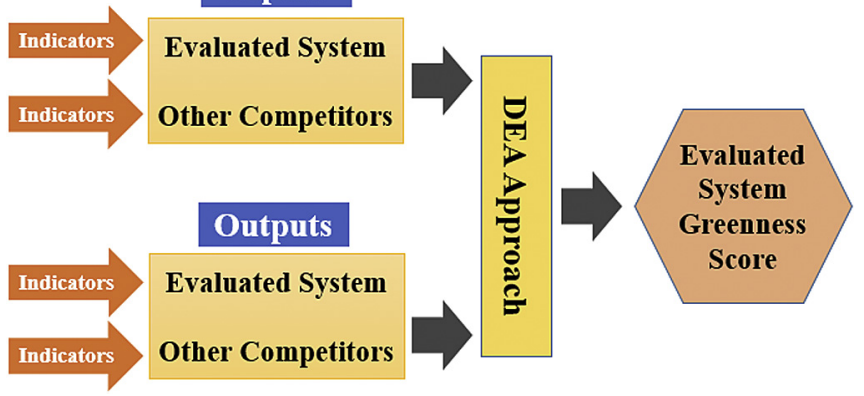

Fig. 5. DEA implementation at the IIL. 
Table 3

Caption of the data for company $\mathrm{ABC}$ used at the CIL assessment in the toolbox.

\begin{tabular}{|c|c|c|c|c|c|}
\hline \multicolumn{6}{|c|}{ Input Data for First General Layer of Assessment. } \\
\hline${ }^{*}$ Arerage percent of solid waste & 0.34 & $\%$ & | ${ }^{\text {Number of produced units }}$ & N/A & units \\
\hline \begin{tabular}{|l|l} 
Arerage percent of waste water \\
\end{tabular} & 8 & $\%$ & Amount of scrap & N/A & Tons \\
\hline \begin{tabular}{|l} 
Arerage percent of disposal rate \\
\end{tabular} & 32 & $\%$ & Amount of planned units & N/A & Tons \\
\hline \begin{tabular}{|l} 
ATrerage percent of GHG \\
\end{tabular} & 2.71 & $\%$ & \begin{tabular}{|l|l} 
Material scrap rate \\
\end{tabular} & 40 & $\%$ \\
\hline - Arerage percent of Industrial Emissions & 21.1 & $\%$ & ${ }^{2}$ Tililization of raw material & 20 & $\%$ \\
\hline \begin{tabular}{|l}
${ }^{*}$ Energgy utilization rate \\
\end{tabular} & 43.4 & $\%$ & \begin{tabular}{|l|l} 
& Percent of reused materials \\
\end{tabular} & N/A & $\%$ \\
\hline \begin{tabular}{|l|l|l}
${ }^{*}$ Electricity efficiency \\
\end{tabular} & N/A & $\%$ & \begin{tabular}{|l|l|l} 
Percent of remork materials \\
\end{tabular} & N/A & $\%$ \\
\hline \begin{tabular}{|l|}
${ }^{*}$ Fuel Productirity \\
\end{tabular} & 47.5 & $\%$ & ${ }^{* \text { Percent of recyled materials }}$ & 92 & $\%$ \\
\hline \begin{tabular}{|l} 
Percent of Solar energy usage \\
\end{tabular} & 0.01 & $\%$ & ${ }^{*}$ Perrent of re-manufactured materials & NAA & $\%$ \\
\hline \begin{tabular}{|l|} 
- Return on environment inrestment \\
\end{tabular} & 4.00 & $\%$ & *Re's Rate & 92 & $\%$ \\
\hline + Environment penalties cost rate & 10 & $\%$ & ¿ Percent of water consumption & 42 & $\%$ \\
\hline \begin{tabular}{|l|l} 
Environmental expenses rate \\
\end{tabular} & $s$ & $\%$ & Eercent of wood consumption & N/A & $\%$ \\
\hline Average raw material perocessed & N/A & Tons & ₹ Percent of other natural resources consump. & N/A & $\%$ \\
\hline \multicolumn{3}{|c|}{ In case of data shortage, please write $N / A$ in the white cell } & E Yatural resources consumption & 42 & $\%$ \\
\hline
\end{tabular}

approach (data transformation) is employed where the undesirable output modeled as being desirable to maintain consistency with input oriented DEA approach implemented. Similar adaptation can be found in (YOU, 2009); (Golany and Roll, 1989); (Gomes and Lins, 2008).

The following steps outline the DEA analysis in IIL of the Greenometer (Yang et al., 2003).

a) Decide on the DMU set, each system to be appraised is called one DMU.

b) Identify the inputs and output of each DMU, each DMU has $m$ inputs and $s$ outputs.

Let the $x_{i j}$ denote the value of the $i$-th input of the $j$-th DMU and $y_{r j}$ denote the value of the $r$-th output of the $j$-th DMU where $i=1,2$, $\ldots ., m ; j=1,2, \ldots ., n ; r=1,2, \ldots ., s$

Let $X_{j}=\left(x_{1 j}, \ldots ., x_{m j}\right)^{T} \geq 0, \quad Y_{j}=\left(y_{1 j}, \ldots \ldots, y_{s j}\right)^{T} \geq 0$

Then $\left(X_{j}, Y_{j}\right)$ can represent the $j$-th DMU.

c) Adopt Charnes, Cooper and Rhodes (CCR) model of DEA to assess the appraised DMU. The greenness level here, which is called DEA efficiency is determined by the following linear programming:

Min. $\theta=\mathrm{V}_{\mathrm{D}}$

s.t. $\sum_{j=0}^{n} x_{j} \lambda_{j}+s^{-}=\theta X_{j 0}$ $\sum_{j=0}^{n} Y_{j} \lambda_{j}-s^{+}=Y_{j 0}$

$\lambda_{j} \geq 0, \quad j=1,2, \ldots . n+1$

$s^{+}=\left(s_{1}^{+}, \ldots, s_{m}^{+}\right) \geq 0 \quad \& \quad s^{-}=\left(s_{1}^{-}, \ldots, s_{s}^{-}\right) \geq 0$

where $\lambda_{j}$ is the weight of the different DMU.

If the optimal value $V_{D}$ is equal to 1 , then the DMU is efficient, and if it is less than 1 , the DMU is suffering from inefficiency.

\section{Greenometer demonstration}

The application of the developed Greenometer was demonstrated through three case studies. An industry representing each of the considered three sectors in the Greenometer was selected for this demonstration. It is important to note that the data used for the Greenometer assessment processing was gathered from the published sustainability reports of the selected companies in each sector. During the assessment process, there were two data sets utilized. The first data set used was in the CIL and it was in the form of percentage values to enable the fair evaluation among different data units and magnitudes coming from different industrial sectors. This normalization process was important in obtaining the desired comparative global greenness metric. The second data set was used in the IIL where specific values in each sector was gathered to assess the relative greenness level of the evaluated company among its peer competitors in this specific industrial sector. In each assessment case, the relative positioning of this industry with respect to the previously mentioned virtual global performance is conducted first through the CIL layer and then another positioning relative to the best performers within the specific sector is followed at the IIL.

\subsection{Greenness assessment for an electronic industry}

The light industries sector is represented in this study by the electronic industries. The selected company for the assessment, $\mathrm{ABC}$, is a multinational electronics company with a great share in the telecommunication market (leading sales of both TVs and mobile phones). ABC greenness data used for the first assessment stage of the Greenometer at the CIL is shown in Table 3.

For the IIL layer, two sets of data were required. The first set of data was for other companies in the same electronics sector that are leading the sector's green performance. This data set as explained in section 3 is used to develop the optimal DMU frontier for the DEA analysis conducted at this stage. Table 4 displays the data gathered

Table 4

Caption of the data for companies used to develop the optimal DMU frontier in the IIL.

\begin{tabular}{|c|c|c|c|c|c|c|c|}
\hline \multicolumn{3}{|c|}{ Green Electronics Indicators } & \multirow[t]{2}{*}{ Units } & \multicolumn{4}{|c|}{ Decision Making Units (DMUs) } \\
\hline & & & & Company 1 & Company 2 & Company 3 & Company 4 \\
\hline \multirow[t]{3}{*}{ Inputs } & 1 & ${ }^{*}$ Energy consumption intensity & TJ/Million \$ & 0.182 & 0.679 & 0.239 & 0.124 \\
\hline & 2 & * Water consumption intensity & K Ton/Million \$ & 0.224 & 0.162 & 0.047 & 0.042 \\
\hline & 3 & * Ozone depleting substances intensity & Kg/Million \$ & 66.7 & 32 & 313 & 0.00296 \\
\hline \multirow[t]{4}{*}{ Outputs } & 1 & * GHG emission intensity & Ton CO2/Million \$ & 0.039370079 & 0.070921986 & 0.062893082 & 0.067114094 \\
\hline & 2 & * Water discharge intensity & m3/Million \$ & 0.004766444 & 0.002918856 & 0.007423905 & 0.014814815 \\
\hline & 3 & * Waste intensity & Ton/Million \$ & 0.280898876 & 3.03030303 & 0.980392157 & 1.612903226 \\
\hline & & Weights & & 1 & 1 & 1 & 1 \\
\hline
\end{tabular}


Table 5

Caption of the DMU Data for company ABC used at the IIL for DEA analysis.

\begin{tabular}{|c|c|c|c|c|c|}
\hline \multicolumn{6}{|c|}{ In Case of Electronics Industry } \\
\hline$\Rightarrow$ Energy consumption intensity & $0.36 \mathrm{~s}$ & $\mathrm{TJ} / \mathrm{MS}$ & : GHG emission intensity & 47.7 & Ton C02/MS \\
\hline I Water consumption intensity & 0.384 & $\mathrm{~K}$ Ton $/ \mathrm{MS}$ & " Water discharge intensity & 515.3 & $\mathrm{~m} 3 / \mathrm{MS}$ \\
\hline † Ozone depleting substances intensity & 0.0514 & Ton/MS & - Waste amount intensity & 3.12 & Ton/MS \\
\hline
\end{tabular}

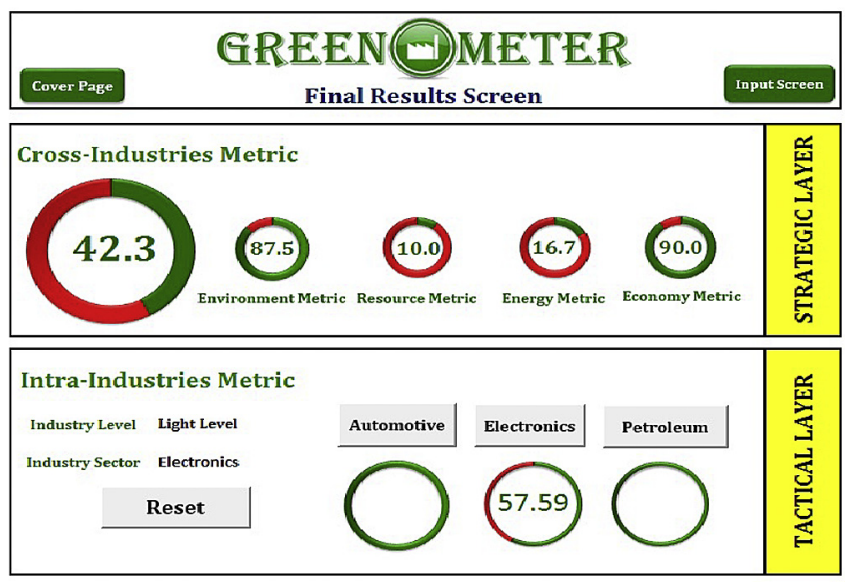

Fig. 6. Caption of the Greenometer assessment output of ABC Electronics Company.

from the top four green performing companies in this sector extracted from their published sustainability report. The same data for the considered $A B C$ Company for assessment is shown in Table 5 .

After having all the required data in the correct format, the Greenometer assessment processes at both layers were carried out Fig. 6 displays the output generated by the Greenometer toolbox for ABC Company assessment.

The assessment scores shown in Fig. 6 points to some interesting observations. First the company had a 42.3 score at the CIL This means that if the company is to be compared with a virtual system of an ideal greenness performance at the four considered attributes, it would have $42.3 \%$ of the performance of such system. The relative assessment helps positioning the company in the global sustainability scene and how it would compare to any other company with respect to these four greenness attributes. Second, ABC scored 57.59 at the IIL which means that within this specific electronics industry, $A B C$ Company is performing at $57.59 \%$ relative efficiency to the optimal greenness performance frontier generated form combining the best performance levels of the leading companies in this sector at the considered attributes. Third, analyzing these scores highlights how the developed Greenometer can aid manufacturing managers not only in understanding their position in the context of green manufacturing (as outlined in the previous two points) but also in developing a prioritized plan of required greenness improvements. For example, the low score of resource attribute at the CIL points to a required attention by $A B C$ to work on their various recycling activities as well as the low score of the energy attribute that highlights the need to investigate the company's energy usages rates and types and work on improving its efficiency. The tactical greenness score of less than $60 \%$ efficiency among $\mathrm{ABC}$ competitors' points to the possibility that the company may be focusing more on new technologies and sales while putting less emphasis on sustainability aspects. The sustainability and profitability paradox can be the reason for this performance.

Table 6

Caption of the data for company EFG used at the CIL assessment in the toolbox.

\begin{tabular}{|c|c|c|c|c|c|}
\hline \multicolumn{6}{|c|}{ Input Data for First General Layer of Assessment. } \\
\hline Average percent of solid waste & 40 & $\%$ & * Number of produced units & N/A & units \\
\hline${ }^{*}$ Arerage percent of waste water & 50 & $\%$ & ${ }^{*}$ Amount of scrap & N/A & Tons \\
\hline${ }^{*}$ Aserage percent of disposal rate & 20 & $\%$ & \begin{tabular}{|l}
${ }^{*}$ Amount of planned units \\
\end{tabular} & N/A & Tons \\
\hline${ }^{*}$ Arerage percent of GHG & 28 & $\%$ & ${ }^{* \text { Material scrap rate }}$ & 30 & $\%$ \\
\hline *Arerage percent of Industrial Emissions & 20 & $\%$ & \begin{tabular}{|l|l|l} 
*utilization of raw material \\
\end{tabular} & 60 & $\%$ \\
\hline${ }^{+}$Energy utilization rate & 80 & $\%$ & \begin{tabular}{|l|} 
Percent of reused materials \\
\end{tabular} & 85 & $\%$ \\
\hline Electricity efficiency & 60 & $\%$ & \begin{tabular}{|l|}
${ }^{*}$ Percent of rerrork materials \\
\end{tabular} & 85 & $\%$ \\
\hline Fucl Productivity & 12 & $\%$ & ${ }^{*}$ Percent of recycled matcrials & 85 & $\%$ \\
\hline Pereent of Solar energy usage & 28.50 & $\%$ & ${ }^{*}$ Percent of re-manufactured materials & 85 & $\%$ \\
\hline - Return on environment inrestment & 3.00 & $\%$ & \begin{tabular}{|c|}
${ }^{-}$Re's Rate \\
\end{tabular} & 85 & $\%$ \\
\hline${ }^{-}$Emvironment penalties cost rate & 2 & $\%$ & ${ }^{2}$ Percent of water consumption & 18 & $\%$ \\
\hline Fnirronmental expenses rate & 3 & $\%$ & ${ }^{{ }^{*} \text { Percent of rood consumption }}$ & N/A & $\%$ \\
\hline${ }^{* \text { Average raw material perocessed }}$ & $\mathrm{N} / \mathrm{A}$ & Tons & \begin{tabular}{|l|} 
*Percent of other natural resources consump. \\
\end{tabular} & N/A & $\%$ \\
\hline \multicolumn{3}{|c|}{ In case of data shortage, please write N/A in the white cell } & * Natural resources consumption & $\frac{18}{18}$ & $\%$ \\
\hline
\end{tabular}

Table 7

Caption of the data for companies used to develop the optimal DMU frontier in the IIL.

\begin{tabular}{|c|c|c|c|c|c|c|}
\hline \multicolumn{3}{|c|}{ Green Automotive Indicators } & \multirow[t]{2}{*}{ Units } & \multicolumn{3}{|c|}{ Decision Making Units (DMUs) } \\
\hline & & & & Company 1 & Company 2 & Company 3 \\
\hline \multirow[t]{4}{*}{ Inputs } & 1 & * Energy consumption per vehicle & MWH/Vehicle & 1.86 & 2.08 & 2.25 \\
\hline & 2 & * Percent of energy from renewable sources & $\%$ & 1.73 & 100 & 51 \\
\hline & 3 & *Water consumption per vehicle & m3/vehicle & 2.81 & 4.9 & 2.18 \\
\hline & 4 & ${ }^{*}$ Recycling material rate per vehicle & $\%$ & 20 & 99 & 95 \\
\hline \multirow[t]{5}{*}{ Outputs } & 1 & ${ }^{*} \mathrm{CO} 2$ emission per vehicle & Ton/vehicle & 1.785714286 & 1.333333333 & 1.515151515 \\
\hline & 2 & *Wastewater per vehicle & m3/vehicle & 0.227790433 & 0.290697674 & 2.127659574 \\
\hline & 3 & ${ }^{*}$ VOC per vehicle & Kg/Vehicle & 0.465116279 & 6.535947712 & 0.775193798 \\
\hline & 4 & ${ }^{*}$ Waste per vehicle & Kg/Vehicle & 0.029171529 & 0.08 & 0.202839757 \\
\hline & & Weights & & 0.841404816 & $\mathbf{0}$ & 0.158595184 \\
\hline
\end{tabular}


Table 8

Caption of the DMU Data for company EFG used at the IIL for DEA analysis.

\begin{tabular}{|c|c|c|c|c|c|}
\hline \multicolumn{6}{|c|}{ In Case of Automotive Industry } \\
\hline - Energy consumption per rehicle & 2.19 & MWH & * CO2 emission per rehicle & 0.83 & Tor \\
\hline${ }_{*}^{*}$ Percent of energy from renemable sources & 48.03 & $\%$ & * Waste water per rehicle & 1.89 & $\mathrm{~m}_{3}$ \\
\hline$\approx$ Water consumption per rehicle & 3.37 & $\mathrm{~m} 3$ & ${ }^{*}$ VOC per rehicle & 3.1 & $\mathrm{Kg}$ \\
\hline " Recycling material rate per rehicle & 99 & $\%$ & * Waste per rehicle & 243 & $\mathrm{Kg}$ \\
\hline
\end{tabular}

\begin{tabular}{|c|c|c|}
\hline Cover Page & Final Results Screen & Input Screen \\
\hline
\end{tabular}
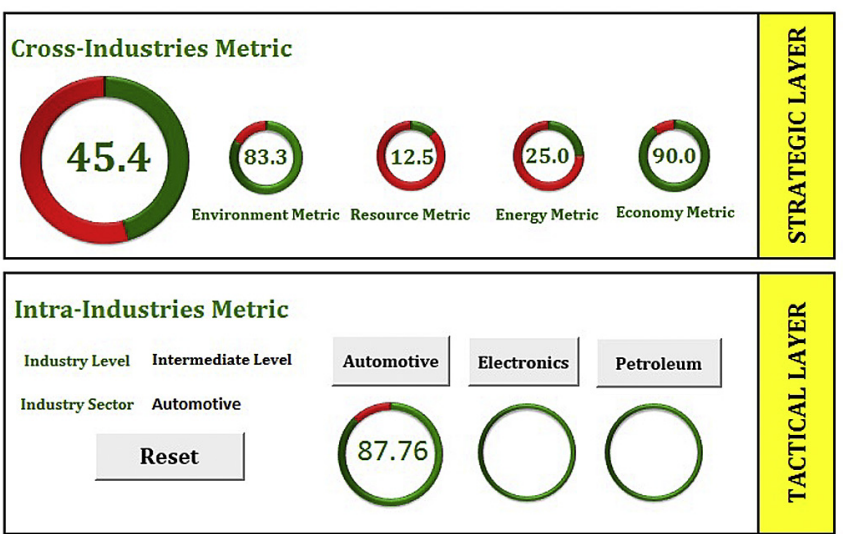

Fig. 7. Caption of the Greenometer assessment output of EFG Automotive Company.

Fourth, the company can use these scores to set a quantitative improvement plans by setting a target score at the CIL (for e.g. moving up to $60 \%$ within 6 months) or at the IIL or even improvement targets for specific attributes. These scores can also be used for tracking improvements along the company's greenness transformation journey.

\subsection{Greenness assessment for an automotive industry}

The medium industries sector is represented in this study by the automotive industry. EFG is a leading North American automotive company that will be considered for assessment. Data for the CIL assessment is shown in Table 6.

The same two sets of data as in the electronic company's case were needed in the automotive assessment case. The optimal frontier was developed in the DEA analysis of this layer using greenness performance data of three leading automotive companies both in North America and Europe. The IIL data used to for the DEA of the other automotive companies and the one for EFG are listed in Tables 7 and 8 respectively.

Fig. 7 displays the output generated by the Greenometer toolbox for EFG Company assessment after data processing at both the CIL and IIL.

Looking at EFG assessment score, it can be noticed that it is close in its global performance (45.5\% of the ideal virtual system) to ABC Electronic Company. This highlights how the Greenometer can be used to compare industries of different sectors using a relative assessment. The IIL score indicates the EFG is well positioned among its competitors in the automotive sectors with around $88 \%$ relative efficiency to the optimal frontier generated by the best performance levels within the sector. The gap between the two scores also highlights how both level of assessments are important to give a complete picture to green manufacturing mangers of the company is performing and not being misled by either it's inter or intra-industry position. Another interesting observation is the difference between the high score of the environment attribute and the low one for the resource one since

Table 9

Caption of the data for company XYZ used at the CIL assessment of the toolbox.

\begin{tabular}{|c|c|c|c|c|c|}
\hline \multicolumn{6}{|c|}{ Input Data for First General Layer of Assessment. } \\
\hline${ }^{* \text { Average percent of solid waste }}$ & 75 & $\%$ & *Number of produced units & $\mathrm{N} / \mathrm{A}$ & units \\
\hline${ }^{*}$ Arerage percent of waste mater & 45 & $\%$ & ${ }^{* \text { Amount of scrap }}$ & N/A & Tons \\
\hline $\begin{array}{l}{ }^{*} \text { Arerage percent of disposal rate } \\
\end{array}$ & 60 & $\%$ & \begin{tabular}{|l}
${ }^{A}$ Amount of planned units \\
\end{tabular} & N/A & Tons \\
\hline${ }^{{ }^{A} \text { Arerage percent of GHG }}$ & 87.4 & $\%$ & ${ }_{{ }^{\text {Material serap rate }}}$ & 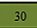 & $\%$ \\
\hline${ }_{{ }^{*} \text { Arerage percent of Industrial Emissions }}$ & 90 & $\%$ & TUtilization of ram material & 61.7 & $\%$ \\
\hline${ }^{{ }^{\prime} \text { Energy utilization rate }}$ & 49 & $\%$ & ${ }^{*}$ Percent of reused materials & N/A & $\%$ \\
\hline${ }^{+}$Electricity efficiency & 14 & $\%$ & \begin{tabular}{|l|l}
${ }^{*}$ Percent of remork materials \\
\end{tabular} & N/A & $\%$ \\
\hline${ }_{- \text {Fuel Productivity }}$ & 56.4 & $\%$ & - Percent of recycled materials & N/A & $\%$ \\
\hline "Percent of Solar energy ysage & 53.00 & $\%$ & \begin{tabular}{|l|}
${ }^{*}$ Percent of re-manuffactured materials \\
\end{tabular} & N/A & $\%$ \\
\hline${ }^{{ }^{*} \text { Return on enironment inrestment }}$ & 20.00 & $\%$ & ${ }^{* \text { Re's Rate }}$ & 60 & $\%$ \\
\hline${ }^{{ }^{*} \text { Environment penalties cost rate }}$ & 50 & $\%$ & ${ }_{*}^{*}$ Percent of water consumption & so & $\%$ \\
\hline${ }^{*}$ Encironmental espenses rate & 45 & $\%$ & \begin{tabular}{|l|l|} 
Percent of rood consumption \\
\end{tabular} & N/A & $\%$ \\
\hline${ }_{{ }^{2} \text { Arerage raw material perocessed }}$ & N/A & Tons & \begin{tabular}{|l}
${ }^{2}$ Percent of other natural resources consump. \\
\end{tabular} & 49 & $\%$ \\
\hline \multicolumn{3}{|c|}{ In case of data shortage, please trite $N / A$ in the white cell } & * Natural resources consumption & 64.5 & $\%$ \\
\hline
\end{tabular}

Table 10

Caption of the data for companies used to develop the Oil sector optimal DMU frontier in the IIL.

\begin{tabular}{|c|c|c|c|c|c|c|c|}
\hline \multicolumn{3}{|c|}{ Green Petroleum Indicators } & \multirow[t]{2}{*}{ Units } & \multicolumn{4}{|c|}{ Decision Making Units (DMUs) } \\
\hline & & & & Company 1 & Company 2 & Company 3 & Company 4 \\
\hline \multirow[t]{2}{*}{ Inputs } & 1 & ${ }^{*}$ Energy consumption intensity & Million Giga Joules/Billion \$ & 6.76 & 4.64 & 2.33 & 3.35 \\
\hline & 2 & * Water consumption intensity & $\mathrm{K} \mathrm{m} 3 /$ Million \$ & 1.14 & 1.78 & 0.47 & 1.29 \\
\hline \multirow[t]{5}{*}{ Outputs } & 1 & ${ }^{*}$ GHG emission intensity & Ton CO2/Million \$ & 0.001941 & 0.00278 & 0.005366 & 0.00462 \\
\hline & 2 & *VOCs intensity & Ton/Million \$ & 1.18 & 1.48 & 3.63 & 1.42 \\
\hline & 3 & ${ }^{*}$ Hazardous waste intensity & Ton/Million \$ & 0.79 & 0.21 & 1.06 & 1.43 \\
\hline & 4 & ${ }^{*}$ Total spills intensity & Barrels/Billion \$ & 0.71 & 0.24 & 1.83 & 1.55 \\
\hline & & Weights & & 1 & 1 & 1 & $\mathbf{1}$ \\
\hline
\end{tabular}


Table 11

Caption of the DMU Data for company XYZ used at the IIL for DEA analysis.

\begin{tabular}{|c|c|c|c|c|c|}
\hline \multicolumn{6}{|c|}{ In Case of Petroleum Industry } \\
\hline * Energy consumption intensity & 15.1 & MGI Eilicon: & *VOCs intensity & 1.2 & Ten/MillionS \\
\hline - Water consumption intensity & 0.7 & Km3 IMilions & *Hazardous waste intensity & 1.7 & Ton/MillionS \\
\hline - GHG emission intensity & 306 & TCCe IMAllion $\$$ & *Total spills intensity & 0.76 & Barelets'Billon s \\
\hline
\end{tabular}
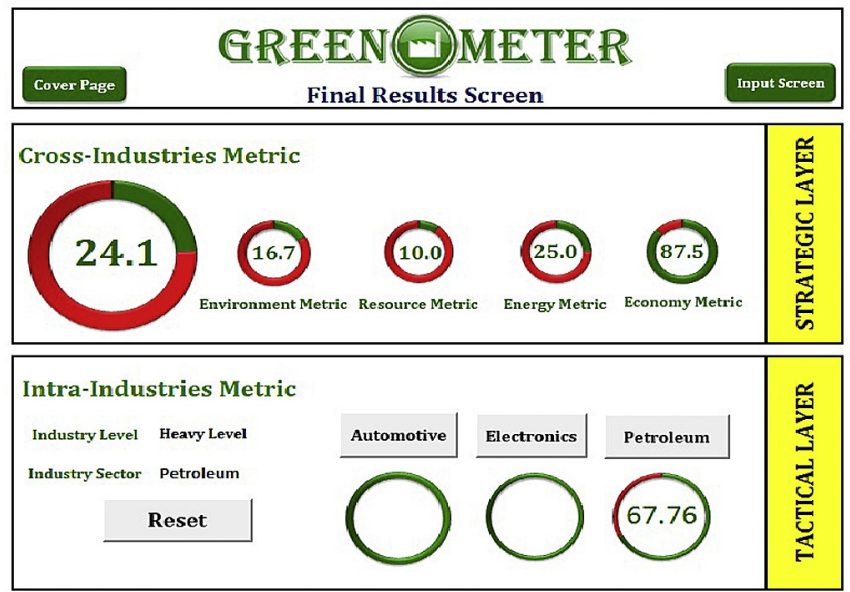

Fig. 8. Caption of the Greenometer assessment output of XYZ Oil Company.

this reflects how more attention is paid to hazardous waste elimination (output) while less attention is paid to the resource efficiency management (input). This sustainability imbalance signal from the Greenometer together with other low scoring indicators and attributes will aid managers in setting their greenness transformation/improvement agenda.

\subsection{Greenness assessment for an oil industry}

The heavy industries sector is represented in this study by the oil industry. XYZ is a European oil company that will be considered for greenness assessment. Data for the CIL assessment is shown in Table 9.

The optimal frontier was developed in the DEA analysis of this layer using greenness performance data of four leading oil companies both in North America and Europe. The IIL data used for the DEA of the other oil companies and the one for $\mathrm{XYZ}$ are listed in Tables 10 and 11 respectively.

Fig. 8 displays the output generated by the Greenometer toolbox for EFG Company assessment after data processing at both the CIL and IIL.

As expected, the CIL very low score reflects the various sustainability challenges that this sector faces globally and how petroleum industry is not an ecofriendly one. The CIL attributes scores also reflects another realty in this sector which is how generally oil companies are far focused on profits than their green footprint when observing the high economy attribute score against all other low scoring attributes. $\mathrm{XYZ}$ is performing with a relative score of $67 \%$ greenness efficiency from the optimal frontier within the industry. Such performance is mainly attributed to the high energy consumption of the company as shown in its IIL data. This shows
Final Comparison of the Selected 3 Case Studies

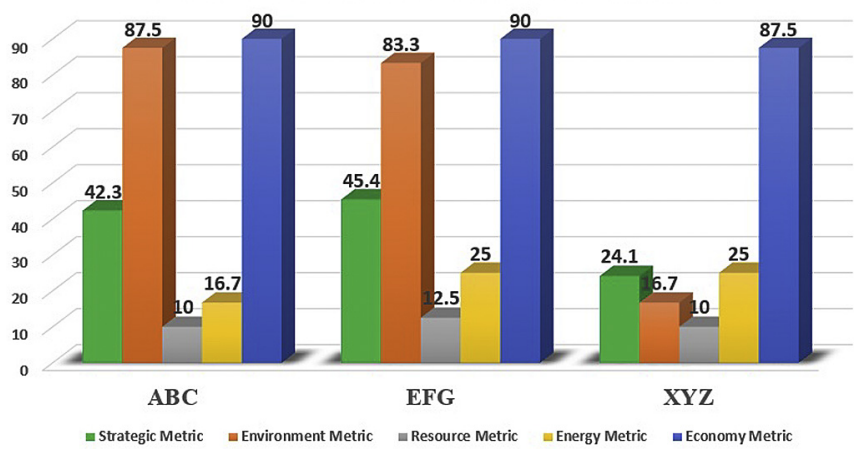

Fig. 9. CIL attributes' scores for the selected case studies.

how helpful the Greenometer analysis can be in highlighting greenness improvement direction as well as setting clear green targets.

\subsection{Greenometer scores comparison across considered industries}

Fig. 9 summarizes the CIL scores for the four selected attributes among the three demonstrated cases. Comparing reported scores, the economic assessment attribute at the CIL had the highest values. This assessment attribute had the lowest weight when environmental experts were surveyed. This discrepancy points to how industries are still lagging behind the required green manufacturing transformation effort and mindset that balances other greenness aspects. Furthermore the type of industry had a clear impact as expected when it comes to the environmental performance. The big gap between the considered heavy industry case and both cases in the light and medium industries suggests prioritization in the greenness effort and support required to this sector. Finally the close scores of the resource attribute among the three cases can make it a good comparative reference between different industries at that strategic greenness level.

\section{Summary and discussion}

The proposed Greenometer aimed at assisting and guiding different managerial levels of various companies in evaluating their current greenness level as well as setting their green transformation plans. For that purpose, an integrated toolbox was developed to assess the relative greenness position of any company among other industries from different sectors as well as within the same sector. The assessment was based on selected greenness attributes and their composing indicators at each of the two levels of the developed Greenometer. Geometric Mean Method (GMM) was adopted to be the generic assessment technique for cross industries greenness evaluation, while Data Envelopment Analysis (DEA) was employed to assess the greenness level of intra-industries layer. Three different industrial applications were used to demonstrate the applicability of the developed Greenometer approach and toolbox. Each case study represented one of the three sectors classified in the Greenometer, namely, light, intermediate and heavy industries.

The reported results of the selected case studies revealed some important findings regarding both; the application of the developed Greenometer as well as the green manufacturing 
transformation efforts. It is important to note that some of these findings are contributed to the context of the selected applications. The applications were meant to be diverse by selecting different industries and thus the generalization of these findings can be acceptable with extra effort of adaptation to maintain objectivity and accuracy. These findings are summarized as follows:

- The Greenometer was shown to be a user friendly platform for evaluating the greenness level of different industrial applications. The greenness relative scores generated from each of the considered cases were helpful in determining the position of each company globally across other different sectors and among its competitors in its specific sector.

- Results showed that the type of industry does not necessary dictate the strategic or global position at the greenness assessment level. For example, the considered light industry case got strategic greenness score lower than the considered intermediate industry case. This also highlights how helpful the Greenometer can be revealing the full position of a company in a global context rather than typically within its own sector.

- An important advantage of the developed Greenometer is that it showed various required areas and directions for green manufacturing improvements and transformation and thus helping in developing a prioritized greenness plan. The CIL pointed to some strategic gaps for the considered cases with respect to a developed ideal global performance. Furthermore, it detailed the scores of each attribute individually to aid planners in deciding on which attribute need to be investigated first. The IIL (through the scores of the different attributes) also pointed to other set of greenness improvement priorities that pertains to the specific sector of the industry.

- The scores of each layer and their attributes not only can act as a planning target but also as an improvement/transformation tracking metric. Such tracking metrics are vital for consistency and alignment of the green manufacturing transformation plans and execution effort.

- In all considered cases, it was observed that the economic assessment attribute at the CIL had the highest values. This assessment attribute had the lowest weight by environmental experts which points to how industries are still lagging behind in the required green manufacturing transformation effort and mindset that balances other greenness aspects.

The resource assessment attribute had lower greenness scores than the environmental one. This can be due to the fact that manufacturing systems still mainly focus more on the environmental indicators of reducing wastes as part of process improvements while less attention is paid to the effect of the resource consumption reduction effort. It can be said that within the scope of the three considered cases, green manufacturing managers are generally focusing more on both environment and economy attributes (outputs) rather than energy and resources attribute (inputs). This observation should play a role in setting the improvement and regulation balanced plans in these fields.

Future work will include expanding the application of the developed toolbox to new sectors to improve applicability and accuracy of the developed approach. Furthermore, integrating more attributes and indicators will be explored to increase the scope of greenness capturing within the Greenometer assessment process. Also increasing the number of different competitors will enhance the accuracy of the final bench marking results. Finally, the current Greenometer allows the evaluation of single system at a time, thus the future improvement should allow for multiple systems to be strategically and tactically evaluated at the same time.

\section{Appendix 1}

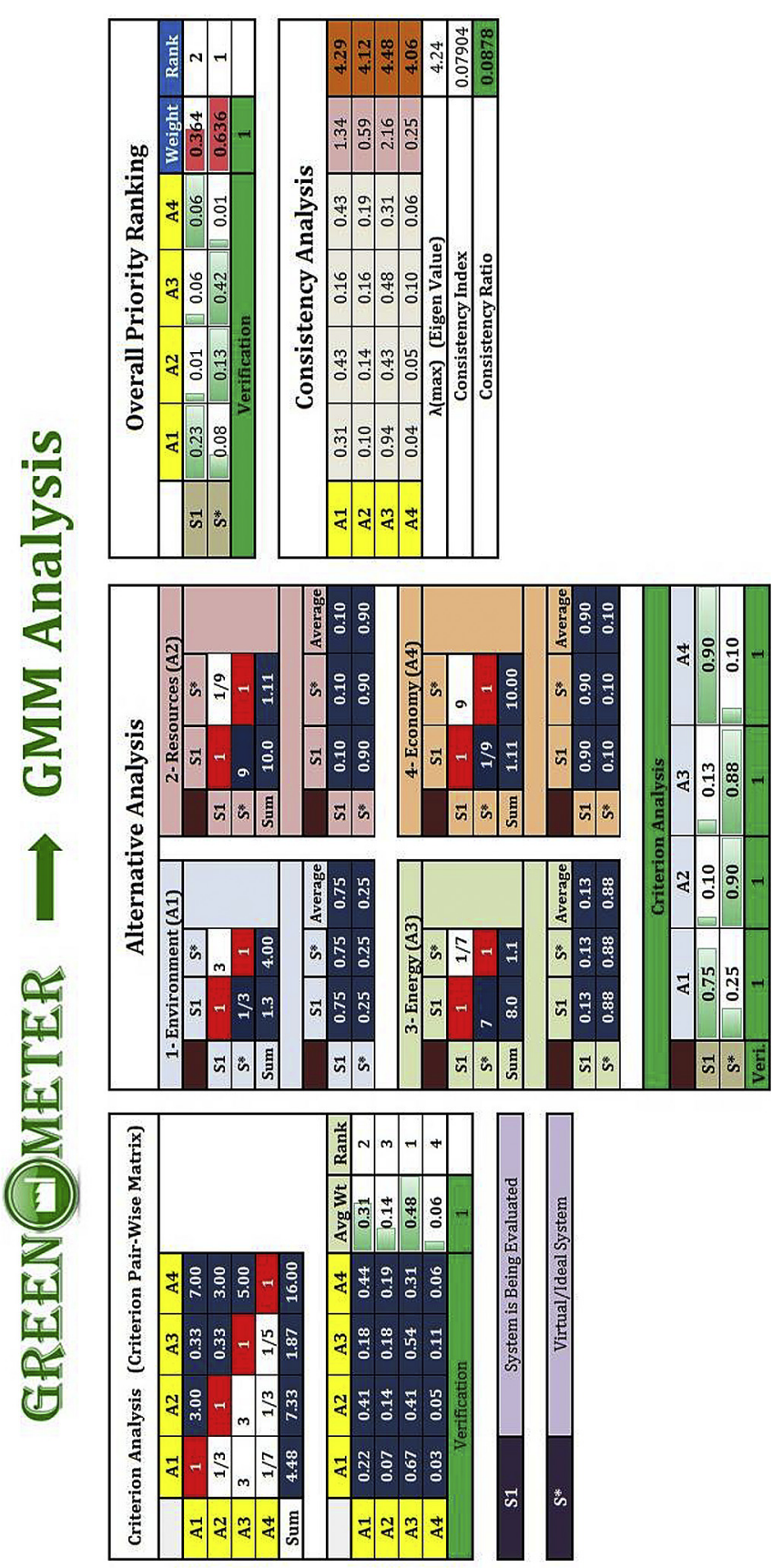

Figure A1. Sample of the overall GMM analysis at the CIL of the developed toolbox. 


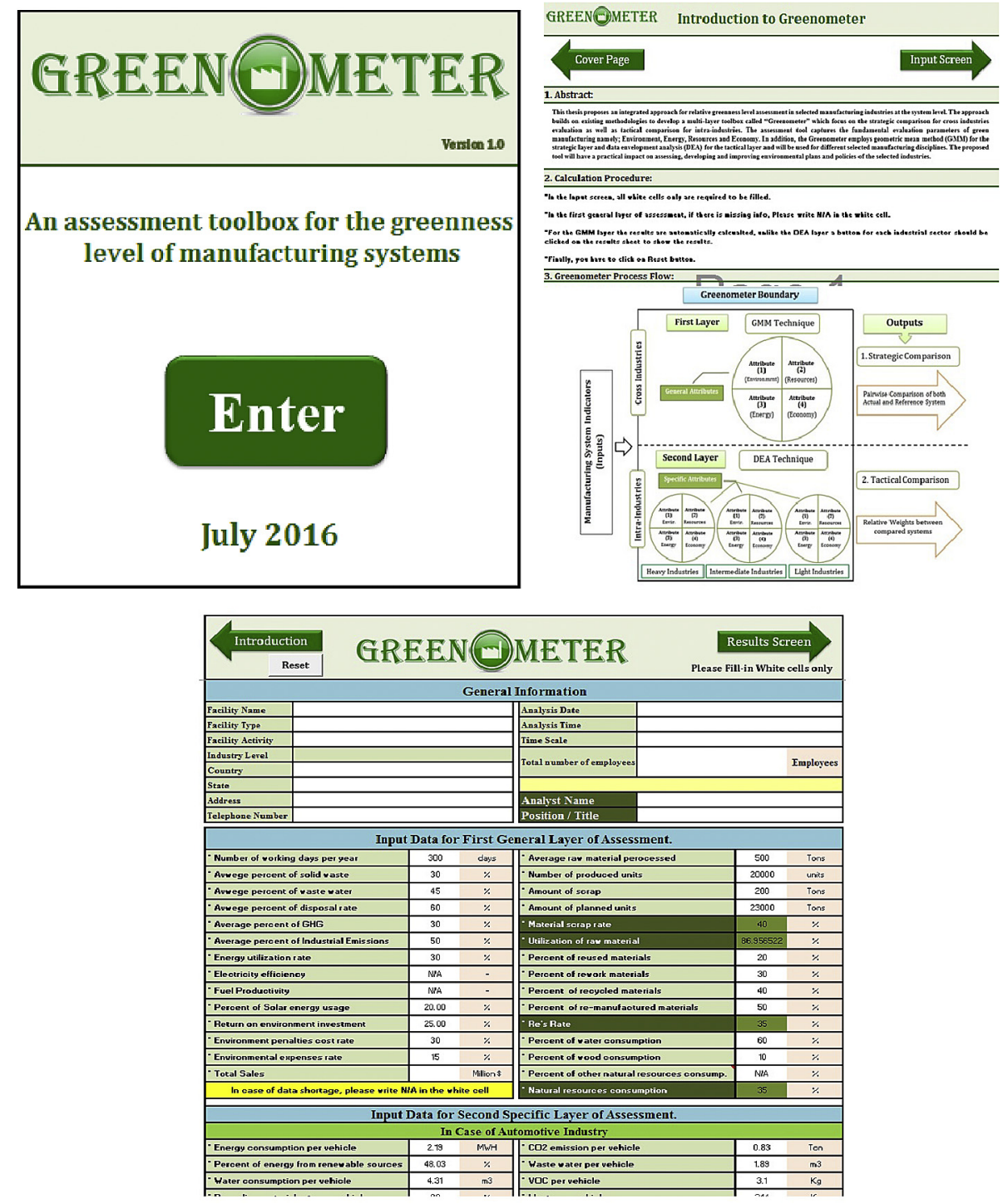

Figure A2. Captions of the GUI if the developed toolbox and the input screens.

\section{Appendix 2}

The calculation process was coded in the developed toolbox based on the following explanation of consistency analysis of Saaty, 1977 as follows: and hence the calculated weights do not represent the experts actual reviews.

The Greenometer consists of 4 different criteria, so the Random Index (RI) of the Greenometer's attributes will be 0.89 as per [Saaty, 1977] RI values given in the following table.

\begin{tabular}{|c|c|c|c|c|c|c|c|c|c|c|c|c|c|c|c|}
\hline $\mathrm{N}$ & 1 & 2 & 3 & 4 & 5 & 6 & 7 & 8 & 9 & 10 & 11 & 12 & 13 & 14 & 15 \\
\hline RI & 0 & 0 & 0.52 & 0.89 & 1.11 & 1.25 & 1.35 & 1.4 & 1.45 & 1.49 & 1.51 & 1.54 & 1.56 & 1.57 & 1.59 \\
\hline
\end{tabular}

Consistency Index (CI) and Consistency Ratio (CR) are calculated. According to [Saaty, 1977], the value of Consistency Index $(\mathrm{CI})=\left(\lambda_{\max }-\mathrm{n}\right) /(\mathrm{n}-1)$, where $\lambda_{\max }$ is the principle Eigen Value (EV) of the attributes' analysis, and $\mathrm{n}$ is the number of attributes. Consistency Ratio (CR) is the ratio between the calculated CI and Random Index (RI) of same size of $n$. Consistency ratio (CR) should be $\leq 0.1$; otherwise, the attributes' analysis matrix is inconsistent,
Random Index (RI) Values [Saaty, 1977].

$\lambda_{\max }=4.24$ and $\mathrm{n}=4$

$\mathrm{CI}=\left(\lambda_{\max }-\mathrm{n}\right) /(\mathrm{n}-1)=(4.24-4) /(4-1)=0.07907$

$\mathrm{RI}=0.89$

$\mathrm{CR}=\mathrm{CI} / \mathrm{RI}=0.07904 / 0.89=0.0878 \leq 0.1$

Hence, the CR is $\leq 0.1$, the expert's data is consistent. “ 


\section{References}

Al-Fandi, L., 2011. A Novel Approach Using LEAN and Simulation Modeling for Effective Green Transformation for High-end Server Manufacturing. Ph.D. dissertation in industrial and system engineering. State University of New York, UMI number 3490333.

Azadeh, A., Amalnick, M., Ghaderi, S., Asadzadeh, S., 2007. An integrated DEA PCA numerical taxonomy approach for energy efficiency assessment and consumption optimization in energy intensive manufacturing sectors. Energy Policy 35, 3792-3806.

Barber, J., 2007. Mapping the movement to achieve sustainable production and consumption in North America. J. Clean. Prod. 15, 490-512.

Charnes, C., Cooper, W., Rhodes, E., 1979. Measuring the efficiency of decision making units. Eur. J. Oper. Res. 2, 429-444.

Deif, A., 2011. System model for green manufacturing. J. Clean. Prod. 19, 1553-1559.

Driscoll, E., Cusack, D., 2013. The development of energy performance indicators within a complex manufacturing facility. Int. J. Adv. Manuf. Technol. 68, 2205-2214.

Golany, B., Roll, Y., 1989. An Application procedure for DEA. Omega 17 (3), 237-250.

Gomes, E., Lins, M., 2008. Modelling undesirable outputs with zero sum gains data envelopment analysis models. J. Oper. Res. Soc. 59 (5), 616-623.

Govindan, K., Diabat, A., Shankar, K., 2015. Analyzing the drivers of green manufacturing with fuzzy approach. J. Clean. Prod. 96, 182-193.

Haapala, K., Zhao, F., Camelio, J., Sutherland, W., Skerlos, J., Dornfeld, D., 2013. A review of engineering research in sustainable manufacturing. J. Manuf. Sci. Eng. 135, 4 .

Hue, T., Yeoa, Z., Nga, R., Tjandraa, T., Songa, B., 2015. A sustainability indicator framework for Singapore small and medium-sized manufacturing enterprises. Proceedings of the $22^{\text {nd }}$ CIRP conference on Life Cycle Engineering. Procedia CIRP 29, 132-137.

Joung, C., Carrel, J., Sarkar, P., Feng, S., 2012. Categorization of indicators for sustainable manufacturing. Ecol. Indic. 24, 148-157.

Linke, B., Corman, G., Dornfeld, D., Tönissen, S., 2013. Sustainability Indicators for discrete manufacturing processes applied to grinding technology. Proc. Soc. Manuf. Eng. 32, 556-563.

Mittal, V., Sindhwani, R., Kapur, P., 2016. Two-way assessment of barriers to leangreen manufacturing system: insights from India. Int. J. Syst. Assur. Eng. Manag. 7, 400. http://dx.doi.org/10.1007/s13198-016-0461-z.

Nordström, E., Öhman, K., Eriksson, L., 2012. Approaches for aggregating preferences in participatory forest planning - an experimental study. open For. Sci. J. 5, $23-32$.
Nouira, I., Frein, Y., Hadj-Alouane, A., 2014. Optimization of manufacturing systems under environmental considerations for a greenness-dependent demand. Int. J. Prod. Econ. 150, 188-189.

Qingsong, W., Xueliang, Y., Dayong, C., Chunyuan, M., Kai, Z., 2010. Research on evaluation Index system for green manufacturing based on PSR model and life cycle. Appl. Mech. Mater. 34-35, 97-84.

Romvall, K., Kurdve, M., Bellgran, M., Wictorsson, J., 2011. Green performance map an industrial tool for enhancing environmental improvements within a production system. Glocalized solutions for sustainability in manufacturing. In: Proceedings of the 18th CIRP International Conference on Life Cycle Engineering. Technische Universität Braunschweig, Braunschweig, Germany, pp. 353-358.

Ruby, P., Alvin, B., 2013. Developing an Expert System for GP Implementation.

Saaty, Th. L., 1977. A scaling method for priorities in hierarchical structures. J. Math. Psychol. 15, 234-281.

Sarkar, P., Joung, C., Carrel, J., Feng, S., 2011. Sustainable manufacturing indicator repository. In: Proceedings of the ASME 2011 International Design Engineering Technical Conference \& Computer and Information in Engineering Conference.

TATA consultancy service (TCS), 2009. Greening for Future, TCS Approach for Metal and Mining Industries.

Teresa, W., John, F., Tom, C., Antonio, M., 2012. Multi-stage DEA as a Measurement of Progress in Environmentally Benign Manufacturing.

Venegas, G., Salgado, J., Díaz-Alvarado, A., 2016. Sustainability indicators for the assessment of eco-industrial parks: classification and criteria for selection. J. Clean. Prod. 133, 99-116.

Vinodh, S., 2011. Assessment of sustainability using multi-grade fuzzy approach. Clean. Technol. Environ. Policy 13, 509-515.

Wang, S., Zhang, L., Liu, Z., Liu, G., Zhang, H., 2005. Study on the performance assessment of green supply chain, proceedings of the IEEE international conference on systems. Man Cybern. 1, 942-947.

Yang, Y., Lu, G., Guo, X., Yamamoto, R., 2003. Greenness assessment of products in PLCA by DEA approach. Mater. Trans. 44, 645-648.

YOU, S., 2009. Development of a Green Index for the Textile Industry: an Application in China. Ph.D. Dissertation. UMI number 3472736.

Zhang, H., Calvo-Amodio, J., Haapala, R., 2013. A Conceptual model for assisting sustainable manufacturing through system dynamics. Proc. Soc. Manuf. Eng. 32, $543-549$.

Ziout, A., Azab, A., Altarazi, S., ElMaraghy, W., 2013. Multi-criteria decision support for sustainability assessment of manufacturing system reuse. CIRP J. Manuf. Sci. Technol. 6, 59-69. 